\title{
Optimization of kinematic parameters in single-sided lapping
}

Optymalizacja parametrów kinematycznych w docieraniu powierzchni płaskich

\section{ADAM BARYLSKI NORBERT PIOTROWSKI*}

DOI: https://doi.org/10.17814/mechanik.2017.10.134

In this paper the influence of selected kinematic parameters on the geometrical results of the singlesided lapping process was presented. The purpose of parameters optimization is to improve the flatness and quality of the machined surfaces. The basic optimization criterion is the uniformity of tool wear. The simulation and experimental results were presented and compared.

KEYWORDS: single-sided lapping, lapping kinematics, abrasive wear, parameters optimization

In the lapping of flat surfaces, it is crucial to maintain the proper condition of the tool. The lapping plate has a significant effect on the dimensional accuracy and shape, as well as on the surface finish quality of workpieces. The main problem that occurs in 1-plate lapping is the uneven wear of the lapping plate resulting in the following flatness deviations: concavity, convexity or axial run-out of the work surface [1-3]. In addition, the lapping process depends on many input parameters. For better performance, research should focus on improving its components or developing new kinematic solutions.

One of the basic mechanisms in the lapping process is the micro-grinding of the material by the abrasive grains. In order to determine the influence of kinematic parameters on the uniformity of wear, numerical simulations of moving grains trajectories are performed. Changing kinematic parameters, such as tool and conditioning rings revolutions, or changing the position of the rings on the plate, changes the shape of these trajectories and thus their density [3-5]. In practice, only the conditioning rings are used in the single-sided lapping to maintain the flatness of the plate. The conditioning time and ring position are controlled and set by the machine operator $[1,6]$.

The purpose of the work is to verify the influence of additional conditioning ring movements in the flat surface lapping system and to develop an unconventional 1-plate lapping system that will control the position, speed and acceleration of the conditioning ring. The system is designed to minimize errors and distortions occurring on the working surface of the lapping plate. The article presents the influence of selected kinematic parameters on the results of the lapping process and optimization of these parameters was performed. The basic criterion was the uniformity of tool wear.

\footnotetext{
* Prof. dr hab. inż. Adam Barylski (abarylsk@pg.gda.pl), mgr inż. Norbert Piotrowski (np.piotrowski@gmail.com) - Politechnika Gdańska, Wydział Mechaniczny
}

\section{1-sided lapping parameters}

The lapping process is very complex and it affects a lot of factors. The input and output parameters of the 1plate lapping are shown in fig. 1. The quality of the geometric surface, tool wear, and process efficiency depend to a large extent (as in all machining operations) on the tool itself (i.e. its geometry and the material from which they were made). In addition, the flatness of the tool is mapped onto the surface of the workpiece [7]. Abrasive slurry is also important in abrasive processing its concentration and volume, and the type and size of grains [8]. Geometry and workpiece material are also important. In addition, the pressure force [9] and the rotational speeds, which are closely related to the parameters and kinematics of the machine tool, have a significant effect on the state of the tool, the quality and the machining efficiency $[5,7,10]$.

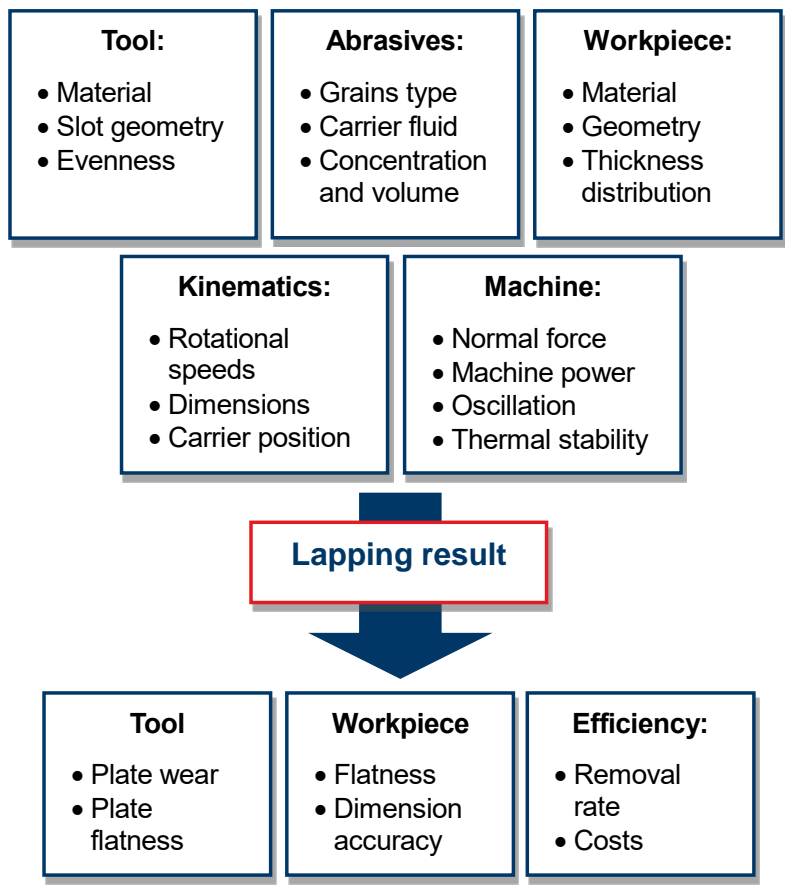

Fig. 1. Input and output parameters of the 1-sided lapping process

\section{Model of the lapping plate wear}

Most developed wear models of the lapping plate assume that the intensity of wear depends on the intensity of the tool contact with the workpiece through abrasive grains $[7,10]$. One way to determine the intensity of contact is to calculate the density of the abrasive grains. It can be predicted that during the lapping process, there are over one million active 
abrasive grains. However, due to the calculation time, the appropriate number of grains should be determined, which reflects the actual number.

Fig. 2 shows an example of calculating the wear of the lapping plate for 5 randomly selected grains. At the initial stage, the grains position in the conditioning ring is generated by a random function (fig. 2a). Then the trajectories of the grains are calculated on the basis of the kinematic equations $[4,5]$ (figs. 2b-c). The interpolation function is used to calculate the set of points that are equally spaced from each other (fig. 2d). The plate area is divided into small squares of equal area. At the last stage, the path density is calculated by means of a statistical function that approximates the total number of points in each square of the surface of the plate (fig. 2e). a)

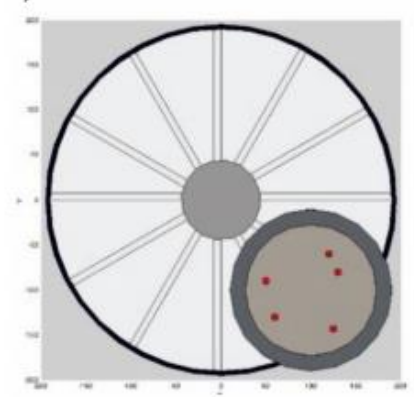

c)

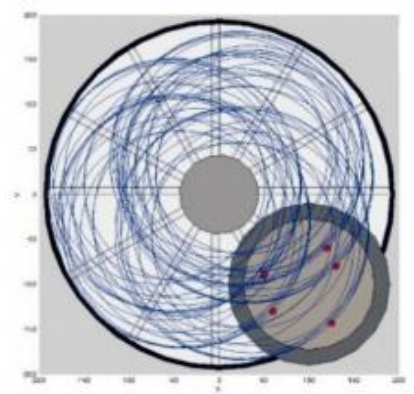

e)

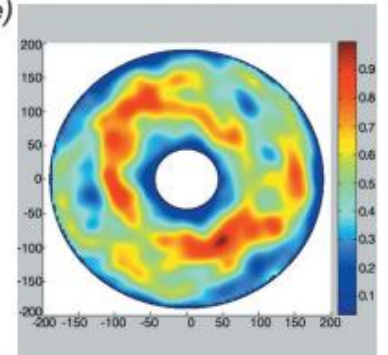

b)

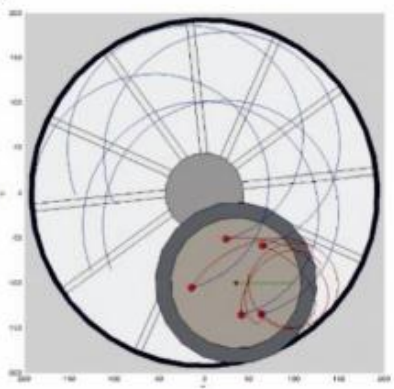

d)

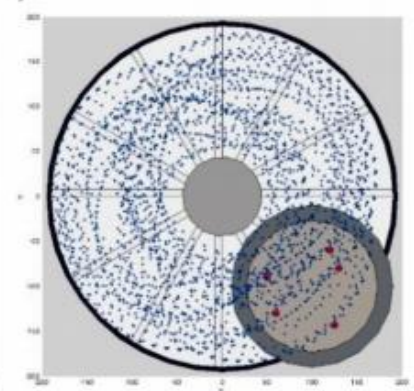

f)

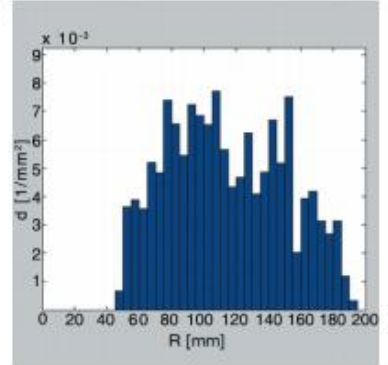

Fig. 2. Steps for determining the density of the trajectory on the lapping plate: a) generation of random abrasives grains, $b-c$ ) generation of trajectories, $d$ ) interpolation of trajectories, e) calculation of trajectory density on the lapping plate, f) profile trajectory density

To determine if the wear causes a concave or convexity of the plate, the intensity of contact is determined for the profile of the plate. This can be achieved by dividing its surface into equal rings of width $r$. The trajectory density is a measure of the points in the corresponding area (fig. 2e) and can be determined from the equation:

$$
D_{i}=\frac{n_{i}}{A_{i}-A_{i-1}}=\frac{n_{i}}{(2 i-1) \pi r^{2}}
$$

where: $n_{i}$ - number of points in the $A_{i}$ field.
The amount of tool wear in the lapping can be described using the Preston tribological model [11]. On the other hand, the equation of the material removal intensity of the grain within each ring, which takes into account the intensity of contact and the velocity of any point on the lapping plate, is:

$$
H_{i}=\frac{k p \sum v_{i}}{(2 i-1) \pi r^{2}}
$$

where: $k$ - Preston coefficient, $p$ - unit pressure, $v$ - speed of the analyzed point.

In 1-single lapping, the $k$-factor and the $p$-force are constant over time. Therefore, when comparing different systems, these values can be omitted. The $S_{D}$ standard deviation of all $H_{i}$ values is given by the formula:

$$
S_{\mathrm{D}}=\sqrt{\frac{\sum_{i}^{N}\left(H_{i}-\bar{H}\right)^{2}}{N-1}},(i=1,2,3 \ldots N)
$$

where: $\bar{H}$ - mean value of the abrasion intensity, $N$ - total number of areas, the lapping plate was divided to [10].

\section{Optimization of kinematic parameters}

Analysis of 1-sided lapping kinematics showed that the basic kinematical parameters have a great influence on the distribution of the abrasive grain trajectories and their speed. In order to maintain the proper flatness of the tool, it is crucial to select the appropriate parameters and optimize them.

The main optimization criterion is the uniformity of the lapping plate $\mathrm{U}$ (maximum value sought):

$$
U=\left(1-\frac{S_{\mathrm{D}}}{\bar{H}}\right) \cdot 100 \%
$$

In order to simplify the optimization of kinematic parameters for 1-single lapping - for standard and reciprocating movement [5] - two dimensionless parameters $-k_{1}$ and $k_{2}-$ were determined:

$$
\begin{gathered}
k_{1}=\frac{\omega_{\mathrm{S}}}{\omega_{\mathrm{t}}} \\
k_{2}=\frac{T_{\mathrm{R}}}{T_{\mathrm{T}}}=\frac{d}{v_{\mathrm{R}}} \frac{\omega_{\mathrm{t}}}{\pi}
\end{gathered}
$$

where: $\omega_{s}$ - angular speed of the guide ring, $\omega_{t}$ - speed of the lapping plate, $d$-duration of the reciprocating speed, $T_{R}$ - period of the single movement of the conditioning ring, $T_{T}$ - period of single rotation of the lapping plate.

The results of simulating the lapping plate wear uniformity for 1000 randomly generated abrasive grains are shown in fig. 3 and fig. 4. Uniformity is calculated for a plate with an external diameter of $350 \mathrm{~mm}$ and an internal diameter of $88 \mathrm{~mm}$. The simulation time was 60 s. The results show that in order to obtain higher uniformity of consumption in the standard system the parameter $k_{1}$ should be about $0.6 \div 0.9$. It has been observed that the trajectories of abrasive grains for these values are pericyclic. For the reciprocating system, the suggested parameters are $k_{1}=0.7 \div 0.75$ and $k_{2}=1 \div 2$. The resulting uniformity is $10 \%$ higher than that of the conventional system. 


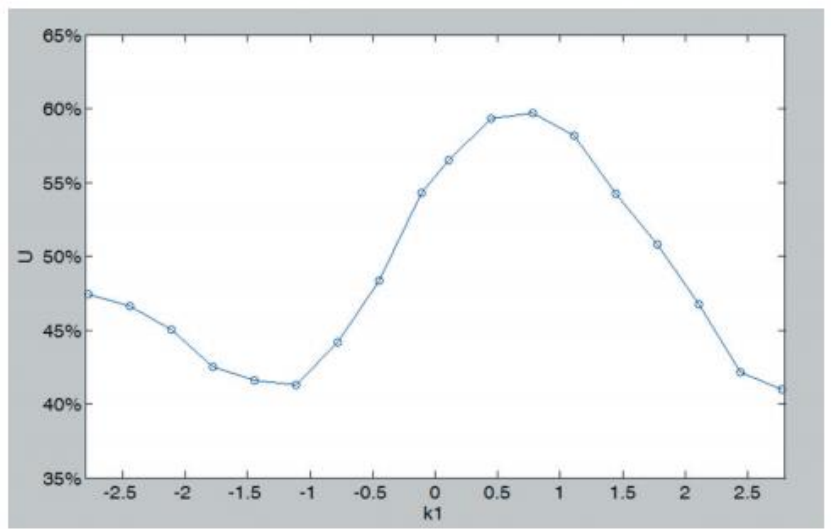

Fig. 3. Graph of wear uniformity $U$ with respect to parameter $k$ for standard 1-disc lapping system (1000 random abrasive grains, radial guiding radius $R=125 \mathrm{~mm}$, simulation time $t=60$ s)

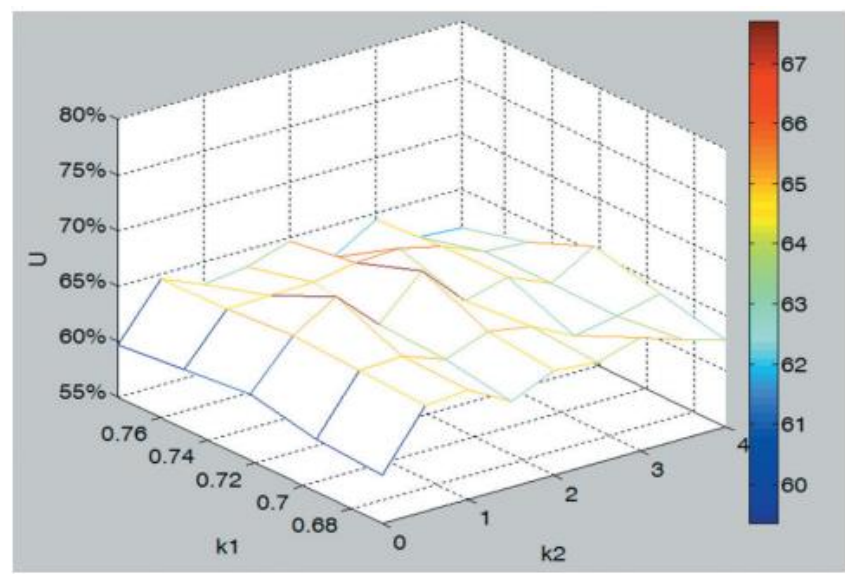

Fig. 4. Graph of wear uniformity $U$ with respect to parameters $k$ and $k_{2}$ for 1 -disk lapping system with reciprocating guide ring (1000 random abrasive grains, simulation time $t=60 \mathrm{~s}$ )

\section{Experiment results}

Experiments were divided into 3 cycles and carried out at a specially constructed laboratory machine [5]. Parameters for each cycle are shown in the table. In each of them, the lapping plate were machined for 30 minutes. The amount of lapping plate wear was measured using a sensor that forms part of the test bench. Measurements were made at 10 points spaced $15 \mathrm{~mm}$ apart one another. The results are shown in fig. 5. The standard deviation, which was $0.0031 \mathrm{~mm}, 0.0020$ $\mathrm{mm}$ and $0.0013 \mathrm{~mm}$, was calculated for each cycle to determine the uniformity of lapping plate wear along the radius for each cycle.

TABLE. Kinematic parameters in subsequent cycles of experiment

\begin{tabular}{|l|c|c|c|}
\hline Lapping cycle & I & II & III \\
\hline Rotational speed of plate $\omega_{\mathrm{t}}, \mathrm{rev} . / \mathrm{min}$ & 55 & 55 & 55 \\
\hline Rotational speed of ring ring $\omega_{\mathrm{s}}, \mathrm{rev} . / \mathrm{min}$ & 35 & 35 & 35 \\
\hline $\begin{array}{l}\text { Minimum distance of the ring from the } \\
\text { center of the plate } R_{\mathrm{min}}, \mathrm{mm}\end{array}$ & 125 & 125 & 125 \\
\hline Length of linear motion $\mathrm{d}, \mathrm{mm}$ & 0 & 150 & 150 \\
\hline Maximum speed of linear motion $\mathrm{v}, \mathrm{mm} / \mathrm{s}$ & 0 & 275 & 550 \\
\hline
\end{tabular}
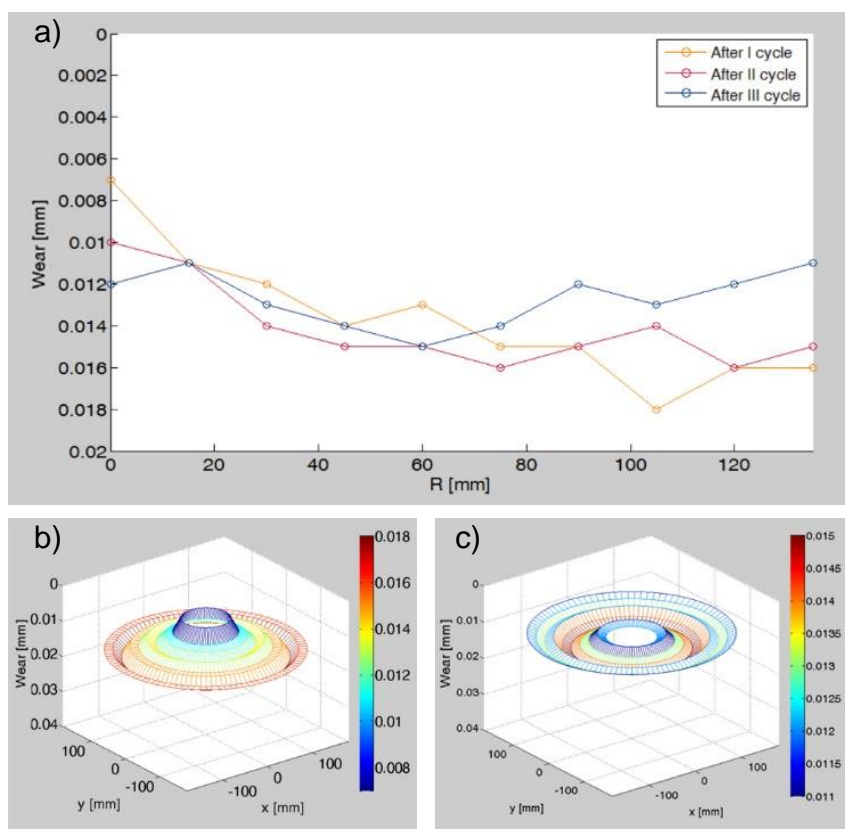

Fig. 5. Lapping plate wear after 3 working cycles: a) profile wear, b) wear shape after first cycle (without additional conditioning ring) c) wear shape after third cycle (with reciprocating conditioning ring)

\section{Conclusions}

It has been noted that the introduction of additional conditioning ring movement in the 1-sided lapping system allows for a more even wear of the lapping plate. The preferred kinematic parameters for the reciprocating system are $k_{1}=0.7 \div 0.75$ and $k_{2}=1 \div 2$. In addition, experimental studies were carried out for standard and reciprocating systems. Of all cycles, standard deviation reached the lowest value for cycle III, using the preferred parameters - in this case, the wear profile was most uniform.

\section{REFERENCES}

1. Uhlmann E., Ardelt T., Spur G. "Influence of kinematics on the face grinding process on lapping machines". CIRP Annals. 48, 1 (1999): pages 281-284.

2. Barylski A. „Podstawy docierania jednotarczowego powierzchni płaskich". Zeszyty Naukowe Politechniki Gdańskiej. Mechanika. 67 (1992).

3. Barylski A. „Obróbka powierzchni płaskich na docierarkach”. Gdańsk: Wydawnictwo Politechniki Gdańskiej, 2013.

4. Barylski A., Piotrowski N. „Koncepcje niekonwencjonalnych układów kinematycznych docierania jednotarczowego z wykorzystaniem robota". Mechanik. 87, 8-9 (2014): pages 36-33.

5. Barylski A., Piotrowski N. „Badania i analiza dokładności powierzchni docieraka docierarki jednotarczowej z ruchem posuwowym pierścienia prowadzącego". Mechanik. 89, 8-9 (2016): pages 1076-1077.

6. Marinescu I.D., Uhlmann E., Doi T. "Handbook of Lapping and Polishing". Taylor \& Francis Publishing House, 2007.

7. Ichikawa K., Ishikawa K., Suwabe H. "A basic study on corrective techniques to recovering accuracy of deteriorated lapping plate". Japan Society of Precision Engineering. 3 (1988): pages 234-236. 
8. Neauport J., Destribats J., Maunier C., Ambard C., Cormont P., Pintault B., Rondeauet O. "Loose abrasive slurries for optical glass lapping". Journal of Optics A: Pure and Applied Optics. 49 (2010): pages 5736-5745.

9. Heisel U., Jakob P. "Research on the workpiece kinematics in face lapping with friction drive". Advanced Materials Research. 565 (2012): pages318-323.

10. Zhao D., Wang T., He Y., Lu X. "Kinematic optimization for chemical mechanical polishing based on statistical analysis of particle trajectories". IEEE Transactions on Semiconductor Manufacturing. 26, 4 (2013): pages 556-563. 